\title{
CLINICAL AND RADIOGRAPHIC EVALUATION OF ELBOWS FROM SPINAL CORD INJURIED PATIENTS
}

\author{
Fabiana de Godor Casimiro ${ }^{1}$, Gabriel Faria de Oliveira ${ }^{1}$, Pedro Henrique de Magalhães Tenório ${ }^{1}$, Isabella da Costa Gagliardi ${ }^{1}$, \\ Américo Zoppi Filho ${ }^{1}$, Alberto Cllquet Junior ${ }^{1}$ \\ 1. Universidade Estadual de Campinas, Faculdade de Ciências Médicas, Department of Orthopedics and Traumatology, Campinas, SP, Brazil.
}

\section{ABSTRACT}

Objectives: To evaluate clinically and radiologically the elbows of spinal cord injured patients and compare them to the control group. Methods: Twenty patients (10 paraplegics and 10 tetraplegics) were clinically evaluated through assessment of pain scale, measurement of active and passive range of motion, degree of muscle strength and MEPS score. They were also submitted to bilateral plain radiography of the elbows. Both groups were compared to the control group. Results: Four paraplegic and three tetraplegic patients referred mild to moderate, sporadic and motion related pain. The control group was asymptomatic.
No statistic significant difference was found in passive range of motion among the three groups. The tetraplegic group showed a lower active range of motion as well as lower MEPS score as compared to the control group. Equal number of patients in the spinal cord injured patients had radiological abnormalities, but those were more severe in the tetraplegic group. Conclusion: Spinal cord injured patients presented clinical and radiological elbow abnormalities, which were more evident on tetraplegics. Level of Evidence III, Case Control.

Keywords: Elbow. Spinal cord injuries. Osteoarthritis. Pain.

Citation: Casimiro FG, Oliveira GF, Tenório PHM, Gagliardi IC, Zoppi Filho A, Cliquet Junior A. Clinical and radiographic evaluation of elbows of spinal cord injury patients. Acta Ortop Bras. [online]. 2016;24(2):77-80. Available from URL: http://www.scielo.br/aob.

\section{INTRODUCTION}

Spinal cord injuries have been increasing over time, having as primary cause accidents with motor vehicles, followed by injuries due to firearms and falls from heights. ${ }^{1}$ They are more frequent in men aged between $15-40$ years old. ${ }^{2}$ The increase in the number of patients with secondary sequelae to spinal cord injuries is due to a highly effective pre-hospital care, which involves control of airways and bleeding, and also spine stabilization. ${ }^{3}$ These precautions allow patients involved in high-energy trauma to survive. Therefore, people who formerly would evolve to death, nowadays survive, but often acquire irreversible consequences, among them spinal cord injuries.

Studies show that the average incidence of traumatic spinal cord injury ranges from 15 to 40 cases per million inhabitants, but in some regions it can reach up to 246 cases/million inhabitants. ${ }^{4}$ In Brazil, the annual incidence of traumatic spinal cord injuries is around 40 cases/million inhabitants, which represents about 6-8 thousand new cases per year. ${ }^{1}$

Tetraplegic and paraplegic patients start to develop physical adaptations in order to perform everyday activities, such as locomotion and transfer. As a consequence, the upper limbs are, therefore, required more intensively, leading to the occurrence of clinical and anatomical changes.

Some studies suggest that regarding upper limbs, shoulder pain is the most prevalent among patients with spinal cord injury, followed by elbow, wrist and hand pain. 5,6

The aim of this study was to evaluate clinically and radiographically elbows of spinal cord injured patients (quadriplegics and paraplegics) and compare the findings to healthy subjects (control group), confronting the data found in the literature.

\section{MATERIALS AND METHODS}

Twenty patients being treated at the Laboratory of Biomechanics and Rehabilitation of the Locomotor System of Hospital das Clínicas da Faculdade de Ciências Médicas da Universidade Estadual de Campinas, Unicamp, SP, Brazil were divided into two groups: 10 paraplegics and 10 quadriplegics. The 20 individuals used solely wheelchairs for locomotion. These patients were evaluated and compared with 10 healthy subjects in the control group. The study project was analyzed by the Ethics Committee of the institution and accepted under CCAE number 23257613.4.0000.5404 The evaluation consisted of a questionnaire with open questions on complaints to the elbows, where patients could

All the authors declare that there is no potential conflict of interest referring to this article.

Work developed at Universidade Estadual de Campinas (Unicamp), Faculdade de Ciências Médicas, Hospital das Clínicas, Laboratory of Biomechanics and Rehabilitation of the Locomotor System, Campinas, SP, Brazil.

Correspondence: Rua Tessália Vieira de Camargo, 126, Cidade Universitária Zeferino Vaz. 13083-887 Campinas, SP, Brazil. fabiana_casimiro@ig.com.br

Article received in 09/21/2015, approved in 10/28/2015.

Acta Ortop Bras. 2016;24(2):77-80 
manifest themselves freely. In cases where there were reports of pain, patients were asked to classify it as mild, moderate or severe, continuous or sporadic and handedness.

Subsequently, the measurement of range of motion (ROM) for flexion-extension and active and passive pronosupination bilaterally, was performed using a goniometer. Muscle strength was classified according to criteria of the American Spinal Injury Association (ASIA), ${ }^{7}$ ranging from zero (no muscle contraction) to 5 (normal motricity and strength). The MEPS questionnaire (Mayo Elbow Performance Score) was also applied. ${ }^{8}$

Finally, all patients underwent plain radiographs of the elbow in the anteroposterior and lateral (profile) views, in the same $\mathrm{RX}$ device and all images were observed by the same computerized radiographic method excluding any possible biases. The images did not show identification on the group they belonged (tetraplegic, paraplegic or control groups) and were evaluated by two members of the Shoulder and Elbow Surgery Society, independently, all at once. Divergent assessments were reassessed by the two experts together in order to reach a consistent classification. The images were classified from zero (no change) to four (severe degenerative changes), according to description provided by Morrey et al. ${ }^{9}$

All patients were instructed on the phases of the study. All participants received and signed the Free and Informed Consent Term, which was also approved by the Unicamp Ethics Committee.

\section{RESULTS}

Thirty subjects were divided into groups - paraplegics, quadriplegics and control group (CG) - with 10 individuals each, eight men and two women. The mean age was 45.4 years old in the paraplegic group, 39.9 years old in the quadriplegic group of and 32.5 years old in the control group. (Table 1) The mean time of injury was 15.7 years in the paraplegic group and 14.1 years in the quadriplegic group. (Table 1) Among the paraplegics we observed two individuals with mild pain and two with moderate pain. Among quadriplegics, two reported mild pain and one reported moderate pain. All pain complaints were sporadic and movement related. There were no complaints of severe pain among all individuals and no pain whatsoever in the control group. Patients who reported pain were evaluated clinically and instructed by the shoulder and elbow orthopedic specialist on how to manage pain. All patients had some degree of pain improvement after the instructions.

As for active ROM, we noticed that the quadriplegic patients tend to have lower ROM as compared to paraplegics and the control group, as shown in Table 2. Assessment of passive ROM showed no significant change between the three groups. (Table 3 )

Regarding the evaluation of muscle strength, we found that paraplegic patients show the same muscle strength than the control group, and that quadriplegics have a decreased degree of bilateral strength. (Table 4)

In the radiographic evaluation of the elbows, no subject from the control group exhibited abnormalities in the images. Some paraplegic and quadriplegic patients had radiographic changes, the left side being slightly more affected than the right side. The tetraplegics were more severely affected according to the rating scale from Morrey et al. ${ }^{9}$ The results are shown in Tables 5 and 6 . The MEPS average score was 100 on CG, 99.5 (95-100) for paraplegics and $81.0(40-100)$ in quadriplegics.
Table 1. Quantification of time of injury and age of individuals, in years.

\begin{tabular}{c|c|c|c}
\hline & Tetraplegic & Paraplegic & Control group \\
\hline $\begin{array}{c}\text { Mean time of injury } \\
\text { (Min - Max) }\end{array}$ & $14.1(2-27)$ & $15.7(9-28)$ & 0 \\
\hline $\begin{array}{c}\text { Mean age } \\
\text { (Min - Max) }\end{array}$ & $39.9(31-48)$ & $45.5(28-68)$ & $32.5(27-50)$ \\
\hline
\end{tabular}

Table 2. Results of active ROM

\begin{tabular}{c|c|c|c}
\hline & Tetraplegic & Paraplegic & Control group \\
\hline Active flexion & Right $127.5^{\circ}$ & Right $147^{\circ}$ & Right $148^{\circ}$ \\
\hline Left $142^{\circ}$ & Left $146.5^{\circ}$ & Left $148^{\circ}$ \\
\hline Active Pronation & Right $53^{\circ}$ & Right $73^{\circ}$ & Right $73^{\circ}$ \\
\hline Active Supination & Left $48.5^{\circ}$ & Left $72.5^{\circ}$ & Left $73^{\circ}$ \\
\hline & Left $59^{\circ}$ & Left $82.5^{\circ}$ & Left $82.5^{\circ}$ \\
\hline
\end{tabular}

Table 3. Results of passive ROM.

\begin{tabular}{c|c|c|c}
\hline & Tetraplegic & Paraplegic & Control group \\
\hline Passive flexion & Right $145.5^{\circ}$ & Right $148^{\circ}$ & Right $148^{\circ}$ \\
\hline & Left $145.5^{\circ}$ & Left $148^{\circ}$ & Left $149.5^{\circ}$ \\
\hline Passive pronation & Right $73^{\circ}$ & Right $74^{\circ}$ & Right $74.5^{\circ}$ \\
\hline Left $73.5^{\circ}$ & Left $73.5^{\circ}$ & Left $74.5^{\circ}$ \\
\hline & Right $79^{\circ}$ & Right $84^{\circ}$ & Right $84^{\circ}$ \\
\hline & Left $78.5^{\circ}$ & Left $83.5^{\circ}$ & Left $84^{\circ}$ \\
\hline
\end{tabular}

Table 4. Assessment of muscle strength.

\begin{tabular}{c|c|c|c}
\hline & Tetraplegic & Paraplegic & Control group \\
\hline Right Biceps & 4.2 & 5 & 5 \\
\hline Left Biceps & 4.1 & 5 & 5 \\
\hline Right Triceps & 3.3 & 5 & 5 \\
\hline Left Triceps & 3.6 & 5 & 5 \\
\hline
\end{tabular}

Table 5. Quantity of individuals with radiographic alterations. Right elbow.

\begin{tabular}{c|c|c|c}
\hline Alteration & Tetraplegic & Paraplegic & Control group \\
\hline Grade 0 & 6 & 6 & 10 \\
\hline Grade 1 & 0 & 2 & 0 \\
\hline Grade 2 & 2 & 2 & 0 \\
\hline Grade 3 & 2 & 0 & 0 \\
\hline Grade 4 & 0 & 0 & 0 \\
\hline
\end{tabular}


Table 6. Quantity of individuals with radiographic alterations. Left elbow.

\begin{tabular}{c|c|c|c}
\hline Alteration & Tetraplegic & Paraplegic & Control group \\
\hline Grade 0 & 5 & 5 & 10 \\
\hline Grade 1 & 1 & 2 & 0 \\
\hline Grade 2 & 3 & 3 & 0 \\
\hline Grade 3 & 1 & 0 & 0 \\
\hline Grade 4 & 0 & 0 & 0 \\
\hline
\end{tabular}

\section{DISCUSSION}

Patients with spinal cord injury have physical limitations that often prevent them from having a normal social interaction, making it difficult interpersonal relationships with family, friends and at work. ${ }^{10}$ The elbow is a ginglymus joint, intolerant to trauma, with high propensity to stiffness and degeneration. Formed by the distal humerus with the trochlea articulating with the olecranon and the capitulum articulating with the radial head. It is surrounded by soft tissue such as anterior and posterior capsule, medial and lateral ligament complex and flexor extensor, pronator and supinator muscles. ${ }^{11}$

Morrey et al. ${ }^{12}$ reported that a functional range of motion during daily activities is between $30^{\circ}$ and $130^{\circ}$ for flexion-extension and $100^{\circ}$ for pronosupination (50 in each direction). The normal range of motion of elbow flexion is $140^{\circ} \pm 5^{\circ}$, pronation is $75^{\circ}$, and mean supination is $80^{\circ}$. Full normal extension should be $0^{\circ} .^{13}$ In normal individuals, the upper limbs are used primarily for prehension. In spinal cord injured individuals the joints are turned into load-bearing joints, as they are required intensely during transfer, propelling the wheelchair and use of crutches, when possible. ${ }^{14}$ Moreover, due to the need of the sitting position, many daily activities need to be performed with the arm above the head, resulting in muscle imbalance and overload. ${ }^{15}$ This overload affects one joint not designed to withstand such loads and possibly presents a muscle imbalance depending on the level of injury, resulting in pain and further, some degree of joint destruction.

The primary osteoarthritis of the elbow mainly affects middle-aged men with higher functional demand on upper limbs. Clinically they may present with pain, muscle weakness and stiffness. X-rays show bone osteophytes mainly in olecranon and coronoid, decreased joint space and, finally, articular degeneration. ${ }^{16,17}$

There is no report in the literature of a classification for elbow osteoarthritis, however, Morrey et al. ${ }^{9}$ refers to the order of appearance of radiographic changes in such cases. First comes a medial osteophytes (humerus-ulnar) displayed on anteroposterior X-ray, classified as grade 1 (Figure 1) Then the osteophytes in the olecranon and coronoid arise, visualized in profile radiographs, classified as grade 2. (Figure 2) Later, changes resulting from joint cartilage wear can be seen, classified as grade 3 . (Figure 3) Finally, loose bodies and deformity in the radial head are seen (Figure 4). We use this radiographic description of the changes, as described by Morrey, to classify the radiographic findings of patients in the present study.

The MEPS score evaluates, indirectly, the quality of life of individuals, based on the quantification of four criteria: pain, range of motion, joint stability and daily life activities. ${ }^{8}$ The final

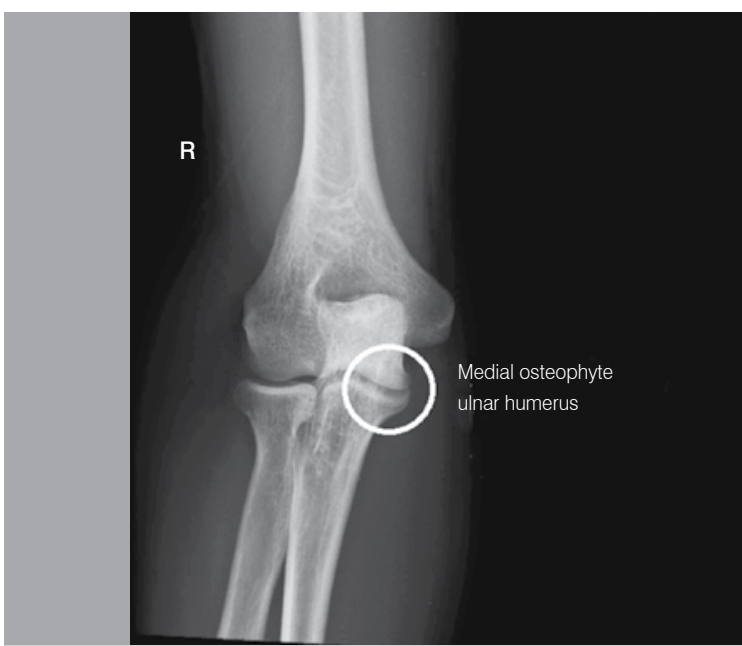

Figure 1. Radiographic alteration grade 1. Presence of medial osteophyte shown in the anteroposterior $\mathrm{X}$-ray.
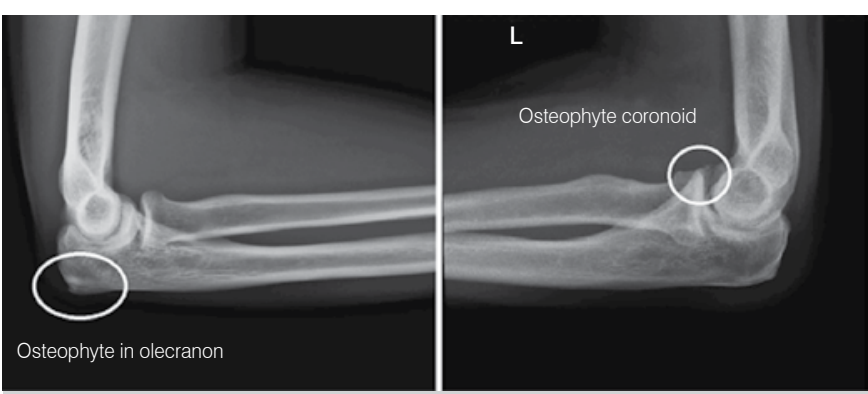

Figure 2. Radiographic alteration grade 2. Presence of osteophyte in olecranon and coronoid, shown in profile X-ray.

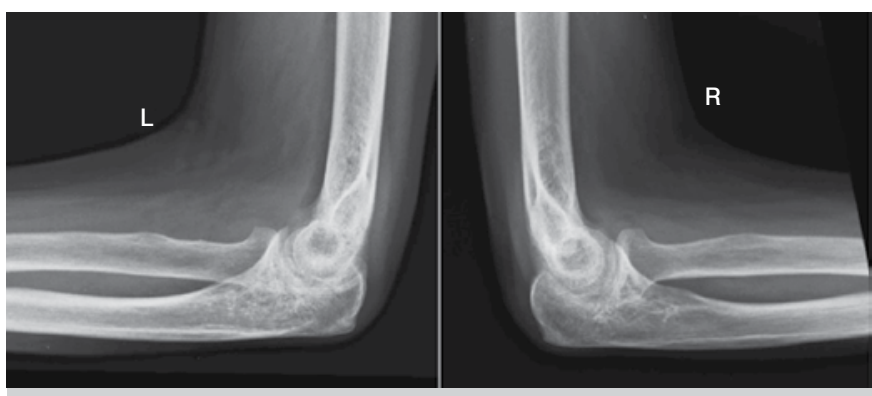

Figure 3. Radiographic alteration grade 3 . Alterations on the articular surface can be seen, but the shape of the radial head is maintained and there are no loose bodies.

sum allows to assess the elbow performance. In our study we observed that paraplegic patients showed an excellent score, as well as the control group (>90), while quadriplegic patients had a mean of 81 , considered as good. This lower figure was mainly due to the limitations t perform daily activities. No patient presented joint instability.

Using the Spearman correlation coefficient, we concluded that the greatest degree of muscle strength of the biceps and triceps is directly related to a better MEPS score (coefficient 0.75 , $p<0.0001)$. There was also a significant correlation between active flexion and MEPS $(0.608, p=0.0004)$ and active supination and MEPS (0.597, $p=0.0005)$. Active pronation and passive ROM have little correlation with MEPS score. The Spearman 


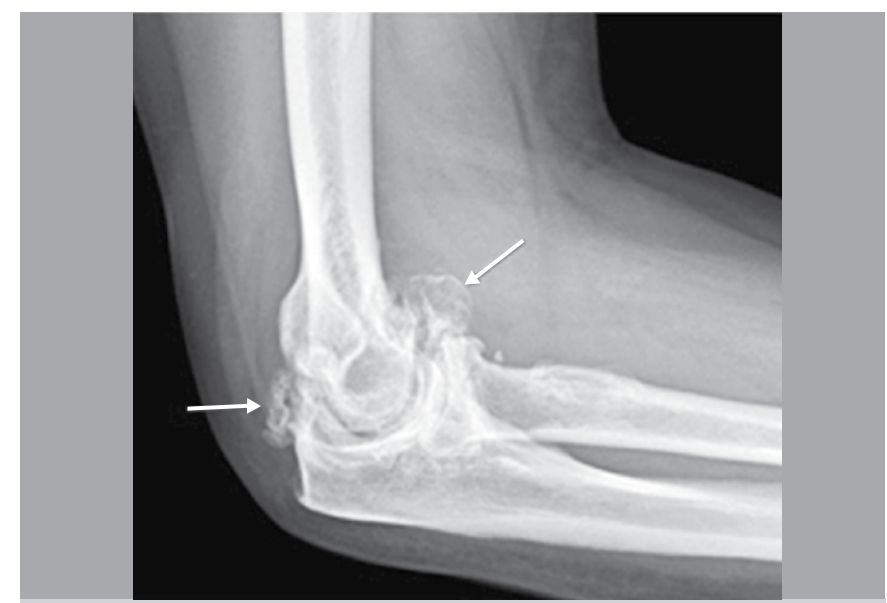

Figure 4. Radiographic alterations grade 4. Articular destruction and loose bodies (arrows). correlation coefficient ranges from -1 , when the correlation between the variables compared is negative, to +1 when the correlation is positive, total. The null value (zero) means no correlation. ${ }^{18}$

\section{CONCLUSION}

This study demonstrated that spinal cord injured patients have clinical and radiographic changes in the elbows, probably due to the overload applied to this joint. Despite having discrete pain complaints, we know that muscle imbalance with diminishing strength can lead to joint instability and consequent degeneration. The fact that there are few studies published on elbows of injured patients leads us to rethink the importance of giving more attention to these patients, especially regarding their quality of life. Therefore, we need to further study the ills that afflict them and try, when possible, to provide greater physical well-being by preventing or delaying the onset of the changes secondary to spinal cord injury.

AUTORS' CONTRIBUTIONS: FGC (0000-0002-9299-0472)*, GFO (0000-0003-3955-1080* and PHMT (0000-0002-0689-221X)* assessed the patients clinically, applying the questionnaire and performing physical exam. FGC and GFO performed the bibliographic search and wrote the article. PHMT and ICG (0000-0002-5508-5203)* referred patients to radiology and collected the exams. AZF (0000-0002-8704-8378)* and ACJ (0000-00029893-5204)* reviewed the text. ${ }^{*}$ ORCID (Open Research and Contributor ID).

\section{REFERENCES}

1. Brasil. Ministério da Saúde. Secretaria de Atenção à Saúde. Departamento de Ações Programáticas Estratégicas e Departamento de Atenção Especializada. Diretrizes de Atenção à Pessoa com Lesão Medular. Brasília: Ministério da Saúde, 2013. [Acessado em agosto de 2015]. Disponível em: http://bvsms. saude.gov.br/bvs/publicacoes/diretrizes_atencao_pessoa_lesao_medular.pdf.

2. Defino HLA. Trauma raquimedular. Medicina, Ribeirão Preto, out./dez. 1999. [Acessado em julho de 2015]; 32:388-400. Disponível em: http://revista.fmrp. usp.br/1999/vol32n4/trauma_raquimedular.pdf

3. Ali J, Adam RU, Gana TJ, Bedaysie H, Williams JI. Effect of the prehospital trauma life support program (PHTLS) on prehospital trauma care. J Trauma. 1997;42(5):786-90.

4. Furlan JC, Sakakibara BM, Miller WC, Krassioukov AV. Global incidence and prevalence of traumatic spinal cord injury. Can J Neurol Sci. 2013;40(4):456-64.

5. Dalyan M, Cardenas DD, Gerard B. Upper extremity pain after spinal cord injury. Spinal Cord. 1999;37(3):191-5.

6. Sie $\mathrm{IH}$, Waters RL, Adkins $\mathrm{RH}$, Gellman H. Upper extremity pain in the postrehabilitation spinal cord injured patient. Arch Phys Med Rehabil. 1992;73(1):44-8

7. American Spinal Injury Association. International Standards for Neurological Classification of Spinal Cord Injury (ISNCSCI). [Acessado em Maio de 2014]. Disponível em: http://www.asia-spinalinjury.org/elearning/ASIA_ISCOS_high.pdf

8. Orthopaedic Scores. MAYO Elbow Score. [Acessado em Maio de 2014]. Dis- ponível em: http://www.orthopaedicscore.com/scorepages/mayo elbow.html

9. Tompkins RB. Nonrheumatoid Inflammatory Arthritis. In: Morrey BF. The elbow and its disorders. 3rd ed Philadelphia: Saunders Company; 2000. p. 795-6

10. Murta SG, Guimarães SS. Enfrentamento à lesão medular traumática. Estud Psicol. (Natal). 2007;12(1):57-63.

11. Nandi S, Maschke S, Evans PJ, Lawton JN. The stiff elbow. Hand (N Y) 2009;4(4):368-79.

12. Morrey BF, Askew LJ, Chao EY. A biomechanical study of normal functional elbow motion. J Bone Joint Surg Am. 1981;63(6):872-7.

13. Motta Filho GR. Cotovelo.In: Barros Filho TEP, Lech O. Exame físico em ortopedia. 2a.ed. São Paulo: Sarvier; 2001. p. 147-9.

14. AAOS- Ortholnfo. Osteoarthritis of the elbow. 1995-2015 [Acessado em abril de 2015]. Disponível em: http://orthoinfo.aaos.org/topic.cfm?topic=A00421

15. Gianini PES, Chamlian TR, Arakaki JC. Dor no ombro em pacientes com lesão medular. Acta Ortop Bras. 2006;14(1):44-7.

16. Cheung EV, Adams R, Morrey BF. Primary osteoarthritis of the elbow: current treatment options. J Am Acad Orthop Surg. 2008;16(2):77-87.

17. Adla DN, Stanley D. Primary elbow osteoarthritis: an updated review. Shoulder Elbow. 2011;3(1):41-8.

18. McDonald JH. Handbook of biological statistics. 3rd ed. Baltimore: Sparky House Publishing; 2014. 